\title{
Control cognitions as predictors of distress in a cross-cultural context
}

Negative psychological states as well as happiness belong
to universal human experience; however, research findings
reveal interindividual and intercultural differences in their
symptoms and effective ways of coping. The aim of this
article is to analyze the experience of distress in a cultur-
al perspective with special focus on the relationship with
control cognitions. Models of agency and Michel's theory
of uncertainty are used to interpret differences in attitude
toward ambiguity and subjective need of control, indicat- ed by preliminary cross-cultural studies. Finally, practical implications of the findings are discussed, pointing out that effectiveness of commonly used psychological interventions, based on the change in control beliefs, may not be universal.

\section{KEY WORDS}

models of agency; psychological distress; personal control; culture

organizations - Department of Psychology, Faculty of Philosophy, Trnava University in Trnava, Slovakia AUthors' CONTRibution - A: Study design - B: Data collection - C: Statistical analysis - D: Data interpretation .

E: Manuscript preparation - F: Literature search · G: Funds collection 


\section{BACKGROUND}

"Culture is more important now than it has ever been", says Gurung (2010), who applies a cultural approach in his monograph on health psychology. Positive and negative emotions, subjective well-being and distress, satisfaction and dissatisfaction with life, also represent an integral part of universal human experience and as such are in the center of research interest in many areas of psychological science.

Efforts to improve the quality of life and eliminate negative psychological states are shared by representatives of various cultures. On the other hand, most research on psychosocial predictors of health was conducted in the USA or Western European countries, and the conclusions as well as underlying interventions have been uncritically generalized to individuals from different cultural backgrounds and socio-economic conditions. Considering these issues, Sue and Sue (2003) use the term "scientific racism". In the context of enhanced globalization and considering the expansion of psychological science into geographical areas that do not belong to so-called mainstream, there is a growing need for knowledge of common and specific characteristics of human experience and behavior, which can be used as an important basis for culturally adjusted interventions and universally valid theories. Health professionals should search for an appropriate way to facilitate achievement of these goals, while respecting the uniqueness, social network and cultural background of the individual.

The aim of this study is to highlight the intercultural differences in the experience of psychological distress, with a special focus on cultural differences in control cognitions and types of agency, which are considered to be an important predictor of distress, as well as the subject of numerous psychological interventions, the effectiveness of which may not be universal.

\section{CULTURE AND PSYCHOLOGY}

Cultural context is considered to be one of the main determinants of human personality. Human behavior, thinking, feeling and relating to other people, interpersonal interactions and participation in social groups are realized by culturally specific language. Hofstede uses computer terminology and defines culture as software of the mind with human nature being the operating system, which determines the basic physical and psychological functioning of an individual (Hofstede \& Hofstede, 2007). Markus and Kitayama (2004) point out the reciprocal relationship between personality and culture, where the differences in socio-cultural environment are accompanied by corresponding psychological differences.
Nowadays the role of culture in human experience and behavior attracts the attention of representatives of psychological disciplines, including health psychology (Draguns \& Tanaka-Matsumi, 2003).

Knowledge of the variability and dynamic character of cultural phenomena encouraged efforts to define dimensions that would emphasize the common and specific features of cultures and allow their comparison. Based on the research findings, Hofstede established five cultural dimensions, with the dimension of individualism-collectivism being the most studied and used as the framework for understanding cultural differences in various areas. According to Hofstede, individualism and collectivism represent two antagonistic value orientations (Hofstede \& Hofstede, 2007). Unlike his followers (Triandis, 1995; Sharma, 2010), he conceptualizes them as two poles of a single dimension, but at the individual level acknowledges the existence of two separate dimensions. The bases of the individualistic orientation in the countries of Western Europe were established in the $13^{\text {th }}$ century during the period of Humanism and the Renaissance. These values were further developed by immigrants, who settled down in North America (Markova et al., 1998). A high level of individualism is typical for the cultures of Australia, the UK, and other Western European countries, while low individualism (or high collectivism) was found in Latin American and East Asian cultures (Hofstede \& Hofstede, 2007).

Personal goals and autonomy represent dominant values of individualistic society, whereas maintaining interpersonal harmony is a guiding principle of everyday life in collectivist cultures (Yamaguchi, 2001; Schwartz, 1994). Individualists struggle to achieve individual goals, while altruism, sacrifice and selfless behavior depend on subjective decisions. On the other hand, people from collectivist cultures subordinate individual efforts to the goals of the group (Triandis, 1995). Hofstede and Hofstede (2007) describe the range of personal and social characteristics which represent prototypes of individualistic and collectivist culture. These are mainly differences in social behavior and representation, communication style, education, relationship between employee and employer, attitude to ownership as well as the health care system and the utilization and effectiveness of psychological interventions.

\section{PSYCHOLOGICAL DISTRESS IN CULTURAL CONTEXTS}

Psychological distress is a concept that generally refers to negative aspects of emotional experience, usually anxiety, depression, irritability, low self-confidence and social isolation (Ridner, 2004; Jim \& Andersen, 2007). In psychological studies it is often im- 
plicitly understood as an indicator of mental health, but also as a global level of psychopathology. According to other definitions, negative emotional states are accompanied by an absence or decrease in positive emotions and subjective well-being, being cognitively perceived as impaired life satisfaction (e.g. Stewart, Ware, Sherbourne, \& Wells, 1992; Chalk, 2007). The word "distress" is often used to refer to non-specific symptoms of psychopathology (e.g. Mullins et al., 2001). A whole range of inventories and scales have been designed to measure mental health, subjective well-being and quality of life (SF-36, Kessler psychological distress scale) (Svoboda, 1999; Andrews \& Slade, 2007). The screening of pathological symptoms may help to identify individuals who are at risk of developing psychiatric or psychosomatic disorders. The SCL-90 (Symptom Check List) with nine clinical subscales enables more detailed differentiation of symptoms (Holi, 2003). Many researchers emphasize the symptoms of anxiety and depression, using them as key indicators of psychological distress, while other forms of psychopathology are considered to be of less importance (Mirowsky \& Ross, 2002). Some degree of distress (e.g. dysphoria) is usually treated as a normal phenomenon, while increased intensity of symptoms may indicate presence of psychological disease. Considering the complexity of the concept, researchers recommend selecting and measuring more indicators, and subsequently use factor analysis to estimate the global level of distress (e.g. Chalk, 2007; Jim \& Andersen, 2007).

The main limitation of the mentioned theories is their exclusive focus on emotional indicators of distress, while considerably less attention is given to behavioral and somatic symptoms. Inkeles and Levinson (in Arrindell et al., 1997) raised an assumption about cultural variability of attitudes to emotional expression, and since then the specific differences have been a subject of many cross-cultural studies (e.g. Kirmayer \& Young, 1998; Çinarbas \& Aegisdottir, 2010). According to Matsumoto (1991), collectivists express more positive emotions within the reference group (in-group) and more negative emotions towards external groups (out-group). This can be explained by the effort to maintain interpersonal harmony and to differentiate specific features and the unique character of the reference group. On the other hand, individualistic society enables the expression of negative emotions within the reference group, while allowing the manifestation of positive emotions towards external groups.

Representatives of cross-cultural perspective in clinical and health psychology point out that some people tend to express emotions in the form of somatic symptoms (Matsumoto \& Juang, 2007). Although the tendency to somatize has been found in members of different cultures of the world, preliminary research findings indicate increased incidence of somatization in non-Western cultures (Draguns \& Tanaka-Matsumi, 2003). It is possible that it somehow normalizes the experience of distress in cultures where efforts to maintain interpersonal harmony interfere with direct communication of emotions (Çinarbas \& Aegisdottir, 2010). Somatic symptoms prevail in the cultures of South and East Asia, Africa and Latin America, while being overlooked in the cultures of North America and Western Europe, which may be related to Cartesian dichotomization of physical and mental states in Western medicine (Draguns \& Tanaka-Matsumi, 2003). Kirmayer, Dao, and Smith (1998) point out the role of lower availability and prejudice against psychological services, as well as increased social stigmatization of mentally ill in certain cultures. According to Cheung (1989), in traditional Chinese society psychiatric symptoms are not considered to be sufficient reasons to seek help. Somatic symptoms and physical pain can be seen as culturally desirable and medically treatable form of communicating one's emotional problems. Matsumoto and Fletcher (1996) demonstrate a positive relationship between somatization and power distance. A possible explanation is that members of cultures with low power distance are usually more spontaneous when expressing emotions.

Different attitudes towards somatic and psychological symptoms can lead to diagnostic errors and inaccurate data about the incidence of certain psychiatric disorders. Official nosology, represented by the western diagnostic systems (ICD-10 and DSM-IV), influences the clinical judgment and experience of health professionals from the countries of the psychological mainstream. The dichotomization of somatic and psychological symptoms is pronounced in the special diagnostic category of somatoform disorders, which somehow challenges the possibility of parallel occurrence of both types of symptoms (Kirmayer et al., 1998). On the other hand, the concept of masked depression, although not being an official diagnostic category, offers a clinical image of emotional distress, which is expressed through somatic symptoms. Besides the inadequate research findings, undervaluation of psychological etiology of somatic complaints can have a negative influence on the patients not receiving appropriate treatment, which can result in decreased quality of life, increased tendency to suicidal behavior as well as higher health costs (Miodek, Szemraj, Kocur, \& Ryś, 2007).

The findings of Matsumoto and Hearn confirm the validity of the collectivist model in certain countries of Central Europe (in Matsumoto \& Juang, 2007). Despite the fact that the area of Central and Eastern Europe (or countries of the former communist bloc) is often overlooked in cross-cultural research, based on the knowledge about common characteristics with non-Western countries (e.g. stigma of mental illness, higher power distance and predominantly collectiv-
Controlling distress: a cultural view 
ist orientation), we can assume higher prevalence of somatization and the related tendency to seek a medical practitioner to treat physical symptoms with psychological etiology.

\section{CONTROL COGNITIONS AND PSYCHOLOGICAL DISTRESS}

Jana Jánošová

An important guideline for counseling and psychotherapeutic practice is the ability to modify emotional experience, but also the general health and quality of life of individuals through a change in the system of beliefs. This approach is reflected especially in rational and cognitive-behavioral approaches. The way an individual controls himself, other people and the environment is considered to be an important part of self-concept and is closely related to the degree of perceived autonomy and self-esteem (Matsumoto, 2001). The type and the degree of control have a significant effect on emotions, motivation and various types of human behavior (Bandura, 1989). Wallston (2004) considers personal control to be a central concept of psychological theory and the need to have the situation "under control" to be a desired way of existence for the majority of people. A couple of research findings indicate that perceived control is more important for one's health than the objective level of controllability.

Thompson (1981) defines personal control as "the belief that an individual has a response in repertoire, which may change, the aversive character of the event" (p. 89). According to Wallston, Wallston, Smith, and Dobbins (1987, p. 5) it is a "belief that individual can manage his internal states and behavior, modify the environment and/or achieve desired goals". Among the most studied control factors are the sense of coherence (SOC) of Antonovsky, hardiness of Kobasa, locus of control of Rotter, Seligman's concepts of learned helplessness and the explanatory style and perceived self-efficacy of Bandura (Heretik, 2007; Křivohlavý, 2001). These concepts are closely related to the individual attitude towards uncertainty, ambiguity and uncontrollable events, which is an important source of perceived need to control the situation.

According to research findings, people with higher self-efficacy have a more optimistic view of life, increased subjective well-being and self-confidence, and a higher degree of social integration. In addition, such individuals perform better in school and display a higher quality of decision-making and motivational processes, which is associated with preference of specific goals, having the character of challenge. On the other hand, low self-efficacy is associated with symptoms of anxiety, depression and perceived stress (Bandura, 1994, 1997; Mathews, 2005; Kononovas \& Dallas, 2009). Furthermore, it can reinforce the negative effect of stress on physiological functioning (e.g. immunosuppression) (Bandura, 1997). According to Krrivohlavý (2001), self-efficacy alleviates the aversive effects of stressful stimuli and situations, being closely related to the quality of life, effective coping strategies and health behavior change. The essential mechanism of the buffering effect is the perception of situations and life events as manageable, but also the ability to control individual feelings of anxiety as well as distressing thoughts (Bandura, 1995).

Control cognitions are in the center of research interest, but are also the aim of many psychological interventions that are applied particularly in Western countries. The ability to actively influence emotional experience and behavior is implicitly connected with the individualistic conception of self, as it supports beliefs about individual independence and autonomy. On the other hand, we can assume that control cognitions would be less important in those cultures which value interdependency and interpersonal harmony even though these represent a potential thread to personal autonomy. These differences are closely related to cross-cultural variability in cognitive functioning. Among the most important are the differences in processes of social perception, due to which an individual perceives himself and the world as separate and independent or interrelated and interdependent entities (Oyserman \& Lee, 2008). Markus and Kitayama (2004) postulate two main types of self-expression, represented by the models of dependent and independent agency that can serve as a framework for interpretation of cross-cultural differences in emotional experience and behavior.

\section{MODELS OF AGENCY AND THE CULTURAL MEANING OF CONTROL COGNITIONS}

Independent and dependent models of agency indicate two different ways of being in the world, creating an implicit cognitive structure of self and social environment as well as the mutual interaction between them (Markus \& Kitayama, 2004). The concept of agency is connected with various types of internal and external activity of self (including processes of control), while the two models reflect socio-cultural beliefs about who is the subject of the activity and which means of acting in the world are considered appropriate in a certain cultural context. In the model of independent agency, active control of one's environment is emphasized. Attitude of the individual is proactive as he actively controls the consequences of his behavior and the main sources of motivation are represented by individual goals, values and beliefs. The model of dependent agency is connected with interpersonal orientation and adaptation to the social environment. Consequences of any activity are de- 
termined and controlled, forming a receptive attitude of the individual trying to adapt his behavior to other people. In this model, social expectation, roles and situations, as well as collective preferences and goals, represent the key motivational sources (Markus \& Kitayama, 2004). Representatives of independent cultures tend to interpret positive events as the result of individual effort, which may increase self-esteem and perceived self-efficacy, while dependent agency enhances the experience of solidarity, sympathy and interdependency (Mesquita \& Markus, 2004). Cognitive and emotional consequences of specific types of agency can influence the experience of distress, as well as the level of life satisfaction and happiness in a certain culture (Lehman, Chiu, \& Schaller, 2004).

Independent agency is an important characteristic of the Euro-American cultural background, with the USA being a prototype of an independently acting culture, while dependent agency is typical for many Asian countries (Hamedani, Markus, \& Fu, 2011; Mesquita \& Markus, 2003). In the mainstream psychological literature, the independent model is sometimes presented as the key to a happy life, personal success and mental health (Markus \& Kitayama, 2004). Mesquita and Markus (2003) point out that the classification of national cultures according to the type of agency is reductionist, as in reality many people apply both models interchangeably, depending on the situation. According to Bandura (2002), dependent and independent agency can co-exist and should not be conceptualized as opposites excluding each other. Most psychological studies apply the independent model, which is seen as primary in Western society. This results in identification of control cognitions with personal control. Although according to expectations the constant increase of individualism should reinforce the autonomy of self as well as the independent agency, Bandura (2002) describes the possible adverse effect of globalization, which can support pursuit of collective goals and interests, creating conditions for the development of dependent agency, as well as some alternative types of control.

Results of intercultural comparisons demonstrate that the model of independent agency is not universally valid and the subject of control influence is not always the individual. Weisz, Rothbaum, and Blackburn (1984) identify two types of control cognitions, which are closely related to the above-mentioned models of agency. The object of primary control is the external reality, and the individual achieves subjective feeling of satisfaction and efficacy by managing his social and physical environment, using personal influence, dominance and even aggression. The subject of secondary control is the individual, trying to adapt to existing conditions. None of these types of agency should be seen as passive, maladaptive or less valuable.

Based on his intercultural theory, Yamaguchi (2001) indentifies three types of control. The subject of personal control is an individual, whose influence on the environment could be direct or indirect. In the case of direct control, the personal influence on the situation is evident, while simultaneously increasing the degree of autonomy and perceived efficacy. The aim of indirect control is the control of one's environment. The individual tries to keep his influence invisible to maintain the state of interpersonal harmony. Proxy control is used when an individual does not have sufficient knowledge, skills and power to manage the specific situation. In such cases an individual delegates control to other competent people. Finally, the subject of collective control is the whole group, while the individual can achieve control and influence as its member. An important characteristic of such cultures is the distribution of responsibility. The concept of personal control, as well as related phenomena (locus of control, self-efficacy, explanatory style), were proposed by U.S. psychologists, and as such represent a positivist perspective in contemporary psychology. Yamaguchi (2001) points out that although most scientists associate the concept of control with the individual, this perspective should not be applied universally. It is possible that the prototype of personal control reflects cultural beliefs about its importance. In individualistic cultures it is preferred to other forms, as it can reinforce the feeling of personal independency. While direct personal control is an attribute of Western society, indirect personal control, collective and proxy control are more prevalent in collectivist countries. Preference of personal efficacy is associated with autonomy, which is the core value of individualistic society, while other types of control could reinforce interpersonal harmony, which is highly valued in collectivistic cultures.

According to research findings, members of collectivistic cultures generally report significantly lower levels of perceived self-efficacy (Scholz, Dona, Sud, \& Schwarzer, 2002; Kononovas \& Dallas, 2009). The study of Chen, Chan, Bond, and Stewart (2006) revealed a negative correlation of self-efficacy with symptoms of depression in adolescents from the USA, whereas in those from Hong Kong a stronger association with interpersonal harmony was found. Oettingen (1995) reports differences in academic efficacy in German, Russian and American schoolchildren. While the lowest values were found in children from East Berlin, the highest self-efficacy was confirmed in the U.S. group. Earley, Gibson, and Chen (1999) presented evidence that collective feedback can help to increase perceived efficacy in Czech managers, while individualized feedback is more effective in the group of American managers. The importance of personal efficacy and increased effort to attain subjective goals reflect cultural bias of mainstream research, which focuses primarily on the individual aspects of personality. Bandura (1997) refutes the claims about
Controlling distress: a cultural view 
the lower importance of self-efficacy in collectivistic countries. Motives of self could not be suppressed; however, in some cultures they are oriented on collective goals. Schaubroeck, Lam, and Xie (2000) recommend distinguishing between individual and collective efficacy, which is based on the trust towards the group. This type of self-efficacy can provide the members of collectivistic cultures with a higher degree of certainty and self-confidence. Bandura (1997) and Oettingen (1995) emphasize that individuals with a collectivist orientation also attain individual goals, which may include achievement of interpersonal harmony or certain benefits for the group.

\section{CONTROL COGNITIONS AND COPING WITH UNCERTAINTY}

The pursuit of acquiring a controlling influence over one's life is determined by the need to avoid uncertainty, and differences in the ways of dealing with ambiguity can be recognized at both the individual and the cultural level. The word uncertainty is used in many areas of science, as well as in the common discourse. Scientific theories of uncertainty have been developed in mathematics, statistics, business and management. From the probabilistic point of view, we can speak about uncertainty when the probability of appearance of an event or a phenomenon is neither equal to zero, nor equal to one. Psychological theories of uncertainty are quite new; however, the need to cope with a certain degree of uncertainty, which is an integral part of human life, has attracted the attention of many psychologists and psychotherapists for decades. Development of socio-cognitive theories has enhanced efforts to study intervening variables with special emphasis on cognitive representations of reality and the individual belief system, which are considered to be significant predictors of emotional experience and human behavior. Subjective perception of a particular situation as uncertain, ambiguous or uncontrollable becomes a potential predictor of distress.

The objective degree of ambiguity in a certain situation, together with the subjective attitude to it, is considered to be an important source of stress (Greco \& Roger, 2003). The research findings show a positive correlation of intolerance of uncertainty with the symptoms of anxiety disorders, as well as other forms of psychopathology (Freeston, Rhe'aume, Letarte, \& Dugas, 1994; Carleton, Norton, \& Asmudson, 2012). Obsessive-compulsive disorder and generalized anxiety disorder are associated with the struggle to acquire certainty, whether by compulsive behavior or by the increased effort to control one's perception of anxiety, distressing thoughts as well as future events (Freeston et al., 1994). Recent studies have demonstrated the role of perceived uncertainty in the pathogenesis of depression by reinforcing development of negative problem orientation (e.g. Yook, Kim, Suh, \& Lee, 2010). Uncertainty may act as a partial moderator of the relationship between neuroticism and symptoms of anxiety disorders and depression (McEvoy \& Mahoney, 2012). Greco and Roger (2003) draw attention to physiological consequences of ambiguous situations and threats. Research findings show that the perception of insecurity could affect the hypothalamic-pituitary-adrenocortical axis as well as the sympathetic nervous system, which can stimulate the development of a somatic disorder.

Uncertainty could be seen as a trans-diagnostic construct, because its influence has been found in a range of psychological and physiological diseases (McEvoy \& Mahoney, 2012). The effect of the ambiguous stimuli on an individual is associated with preferred ways of coping with uncertainty, which are individually and interculturally determined. Interindividual differences in attitudes toward uncertainty are operationalized as the variable of intolerance of uncertainty. It could be defined as a belief that ambiguity, novelty and change are intolerable, since they are sources of potential threat (Frost et al., 1997). According to Buhr and Dugas (2009), it is a personal disposition, expressed by an enhanced tendency to negative reactions in uncertain situations. Cross-cultural differences in the ways of dealing with uncertainty are reflected in Hofstede's dimension of uncertainty avoidance.

Hofstede and Hofstede (2007) apply the findings of Richard Lynn, who described differences in prevalence of anxiety across nations, demonstrating a positive correlation with indices of uncertainty avoidance from the original IBM study. High scores in this dimension are related to increased neuroticism, expressivity and competitiveness. Low scores (or higher tolerance of uncertainty) are associated with lower expressivity and higher incidence of cardiovascular diseases, which may be explained by an increased tendency to repress negative emotions (Hofstede \& Hofstede, 2007; Lynn \& Martin, 1995). Uncertainty avoidance could be defined as "the degree to which the members of certain culture feel threatened by ambiguous or unknown situations" (Hofstede \& Hofstede, 2007, p. 131). According to Mishel (1990), negative connotations of uncertainty are closely related to the philosophy of Western society, which highly values predictability, control and confidence. This can shape the overall orientation of psychological interventions being used in Western countries, the aim of which is to enhance perception of internal control in the client, which can be expressed by different terms (e.g. self-efficacy, mastery, locus of control).

Mishel's conception is based on the chaos theory and proclaims that only instable systems enable activity leading to new and more adaptive forms of organization. Analogously, in conditions of enhanced 
uncertainty (e.g. unpredictable or incurable disease), the patient can develop a new life orientation (Mishel, 1990). Hirsh, Mar, and Peterson (2012) apply the term entropy, originally used in thermodynamics, to express the degree of disorganization in a system. Each self-organizing system is in permanent interaction with the environment by adapting to changing conditions, so that the internal entropy could be maintained at a manageable level. If one integrates the experience of uncertainty and adopts a probabilistic view of the world, one becomes able to see more alternatives and to perceive ambiguous situations as challenges. On the other hand, excessive orientation towards stability prevents the individual from using the experience of uncertainty for personal growth (Mishel, 1990). Hirsh et al. (2012) understand uncertainty as a unique chance to adapt as well as a key motivating factor. While uncertainty can be an important source of distress, individual competence to cope has a positive impact on subjective well-being and happiness.

\section{CONTROL COGNITIONS IN PSYCHOLOGICAL INTERVENTIONS}

Knowledge about the role of control cognitions in prediction of psychological distress and well-being became the basis of many psychological interventions, designed to increase personal efficacy by controlling one's thoughts, as well as verifying new beliefs in real situations. Expectation of personal efficacy is an important source of motivation that determines the degree of effort, as well as the choice of coping strategies, used in certain stress situations (Bandura, 1994). Bandura (1995) emphasizes four sources of perceived control (expressed by the concept of self-efficacy). These are (1) individual mastery, given by past experience of success of failure when coping with a problem; (2) role modeling ("vicarious experience"), based on the observation of other people's performance; (3) verbal persuasion about individual competence to manage the situation, which is often used in psychotherapy; and finally (4) perception and judgment of various physiological cues that can be approached through bio-feedback.

Ability to change individual attributions of control is reflected in cognitive-behavioral therapy (CBT), which is applied in various types of psychological problems as well as somatic diseases. Despite the fact that these interventions are aimed at enhancing personal (individualistic) control, they are considered to be generally effective and applied in different cultures. However, we should keep in mind that these approaches were developed in Western countries, and their theoretical background as well as the model of disease is based on individualistic conceptions (Rathod \& Kingdon, 2009). According to Lewin (2006), the objectives of CBT are closely linked to values of independency and individual autonomy. The efficacy of these interventions has been repeatedly verified, particularly in the Anglo-American context; however, the findings should not be uncritically generalized to different cultures, including minorities within the countries of the psychological mainstream. Psychologists as well as medical staff often disregard the cultural origin of the person who seeks help. Procedures that are routinely used in Western clients may be perceived as inappropriate or even harmful (e.g. the need to express one's emotions) in people from a different cultural background (Seeley, 2000). Rathod and Kingdon (2009) point out that apart from making psychological services more available in the countries that do not belong to the mainstream, it is important to enhance their quality, as well as the cultural competence of helping professionals. Matsumoto and Juang (2007) emphasize the need of cross-cultural validation of psychological theories, as well as the development of culture-free diagnostic methods.

In the process of cognitive-behavioral therapy, the individual actively adopts adaptive patterns of behavior and refines his system of beliefs using cognitive restructuration. Cooperation between the therapist and the client is needed together with maintenance and enhancement of individual autonomy and personal responsibility (Lewin, 2006). Seeley (2000) points out that these objectives may interfere with efforts to preserve common goods and group harmony. A higher degree of collectivism in Eastern countries is often associated with a high power distance that can foster the need for a more directive and educative approach of the therapist, especially at the beginning of the therapeutic process. The client should be guided to disclosure of adequate therapeutic goals, which should not interfere with the goals of the reference group. In the case of eastern cultures it is necessary to respect the personal history of each client, and also to consider possible involvement of the family in therapy (Rathod \& Kingdon, 2009).

Based on these findings, we can expect that approaches aimed to change individual attitudes towards uncertainty would be especially effective in cultures with a higher degree of uncertainty avoidance, including countries of Central and Eastern Europe. These nations share a fair amount of cultural experience with Western Europeans. However, recent findings indicate the existence of certain differences in psychosocial predictors of distress, as well as in the effectiveness of psychological interventions, in comparison with individualistic cultures of USA and Western Europe (e.g. Staudinger, Baltes, \& Fleeson, 1999). Empirical evidence from Eastern and Central Europe is rare and insufficient to make any theoretical conclusions. When interpreting the research findings, it is necessary to consider the potential impact
Controlling distress: a cultural view 
of cultural transition in the post-communist period, during which these countries have undergone significant changes. Varnum and Bowman (in Varnum, 2008) point out the shift toward internal control in Central Europeans, which can be seen mainly in the younger generation, in comparison with only minimal change in the locus of control during the same period in the USA and Western Europe. Extensive cross-cultural validation of previous research findings is needed to develop a more comprehensive view of the experience of distress in people from different cultural backgrounds with special focus on Eastern and Central Europe, but also the other countries of Western Europe (the majority of research in this area has been conducted in the UK).

A frequent object of criticism of Hofstede's theory and related research is the identification of nationality with culture, which can be somewhat reductionist as people of various cultures can be found in a certain state (Sawang, Oei, \& Goh, 2006; Jones, 2007). Despite the fact that indices of cultural dimensions should reflect shared values of the society and according to Hofstede should not be applied to individuals, we can see increased effort to measure the cultural values at the individual level (e.g. Shulruf, Hattie, \& Dixon, 2011). However, the differences in cultural orientation across geographically defined cultures have received only minimal research attention. It is likely that it is the individual cultural orientation (or values) that creates conditions for different efficacy of psychosocial variables, including control cognitions. When choosing an effective psychological intervention, it is desirable to assess both subjective and objective amounts of control, including socio-economic stability and changes in society, as well as the individual attitude towards uncertainty, and then suggest appropriate procedures aimed at modifying the maladaptive beliefs, but also to change adverse living conditions. In this context, cognitive-behavioral methods, psychoeducation and social counseling can be especially useful.

\section{CONCLUSIONS}

Control cognitions represent one of the key psychosocial factors that can help to maintain health and subjective well-being, while buffering the effect of aversive stimuli. Higher levels of perceived control, together with an adaptive attitude toward uncertain and uncontrollable situations, which are viewed as challenges, represent an important sign of personal resilience. Various aspects of personal control are in the center of interest of researchers in the field of health psychology. Results of intercultural studies indicate that the protective effect of control variables may not be universal. Evidence of cross-cultural differences offers a deeper insight into the real meaning of control in a certain social environment. Knowledge of intercultural and interindividual variability must be taken into account when designing psychological interventions as well as preventive activities. Alternative approaches could focus on the positive effects of uncertainty and uncontrollability, understanding of a problematic situation as a challenge, and the utilization of therapeutic methods to stimulate post-traumatic growth.

\section{REFERENCES}

Andrews, G., \& Slade, T. (2001). Interpreting scores on the Kessler Psychological Distress Scale. Australian and New Zealand Journal of Public Health, 25, 494-497.

Arrindell, W. A., Hatzichristou, C., Wensink, J. Rosenberg, E., van Twillert, B., Stedema, J., \& Meijer, D. (1997). Dimensions of national culture as predictors of cross-national differences in subjective well-being. Personality and Individual Differences, 23, 37-53.

Bandura, A. (1989). Human agency in social cognitive theory. American Psychologist, 44, 1175-1184.

Bandura, A. (1994). Self-efficacy. In: V. Ramachaudran (ed.), Encyclopedia of human behavior. Vol. 4. (pp. 71-81). New York: Academic Press.

Bandura, A. (1995). Self-efficacy in changing societies. New York: Cambridge University Press.

Bandura, A. (1997). Self-efficacy: The exercise of control. New York: Freeman.

Bandura, A. (2002). Social cognitive theory in cultural context. Applied Psychology: An International Review, 51, 269-290.

Buhr, K., \& Dugas, M. J. (2002). The intolerance of uncertainty scale: Psychometric properties of the English version. Behavior Research and Therapy, 40, 931-946.

Carleton, R., Norton, M., \& Asmudson, G. (2007). Fearing the unknown: a short version of the IUS. Journal of Anxiety Disorders, 21, 105-117.

Chalk, H. (2007). Mind over matter: Cognitive - behavioral determinant of emotional distress in MS. Psychology, Health and Medicine, 12, 556-566.

Chen, S. X., Chan, W., Bond, M. H., Stewart, S. M. (2006). The effects of self-efficacy and relationship harmony on depression across cultures: Applying level-oriented and structure-oriented analyses. Journal of Cross-Cultural Psychology, 37, 643-658.

Cheung, F. M. (1989). The indigenization of neurasthenia in Hong Kong. Culture, Medicine, and Psychiatry, 13, 227-241.

Çinarbas, C. D., \& Aegisdottir, S. (2010). Somatic, affective and behavioral stress reactions across cultures. International Journal for the Advancement of Counseling, 32, 129-143.

Draguns, J. G., \& Tanaka-Matsumi, J. (2003). Assessment of psychopathology across and within cul- 
tures: issues and findings. Behaviour Research and Therapy, 41, 755-776.

Earley, P. C., Gibson, C. B., \& Chen, C. C. (1999). "How did I do?" versus "how did we do?" Cultural contrasts of performance feedback use and self-efficacy. Journal of Cross-Cultural Psychology, 30, 594-619.

Freeston, M. H., Rhe'aume, J., Letarte, H., Dugas, M. J., Ladouceur, R. (1994). Why do people worry? Personality and Individual Differences, 17, 791-802.

Frost, R., Steketee, G., Amir, N., Bouvard, M., Carmin, C., Clark, D. A., Cottraux, J., Eisen, J., Emmelkamp, P., Foa, E., Freeston, M., Hoekstra, R., Kozak, M., Kyrios, M., Ladouceur, R., March, J., McKay, D., Neziroglu, F., Pinard, G., Pollard, A., Purdon, C., Rachman, S., Rhéaume, J., Richards, C., Salkovskis, P., Sanavio, E., Shafran, R., Sica, C., Simos, G., Sookman, D., Tallis, F., Taylor, S., Thordarson, D., Turner, S., Van Oppen, P., Warren, R., Yaryura-Tobias, J. (1997). Cognitive assessment of obsessive-compulsive disorder. Behaviour Research and Therapy, 35, 667-681.

Greco, V., \& Roger, D. (2003). Uncertainty, stress, and health. Personality and Individual Differences, 34, 1057-1068.

Gurung, R. A. R. (2010). Health psychology: A cultural approach ( $2^{\text {nd }}$ ed.). San Francisco: Cengage.

Hamedani, M. G., Markus, H. R., \& Fu, A. S. (2011). My nation, my self: Divergent framings of America influence American selves. Personality and Social Psychology Bulletin, 37, 350-364.

Heretik, A. (2007). Klinická psychológia [Clinical Psychology]. Nové Zámky: Psychoprof.

Hirsh, J. B., Mar, R., \& Peterson, J. B. (2012). Psychological entropy: a framework for understanding uncertainty-related anxiety. Psychological Review, 119, 304-320.

Hofstede, G., \& Hofstede, G. J. (2007). Kultury a organizace [Cultures and Organizations]. Praha: LINDE.

Holi, M. (2003). Assessment of psychiatric symptoms using the SCL-90 (Doctoral thesis, University of Helsinki, Helsinki, Finland).

Jim, H., \& Andersen, B. (2007). Meaning in life mediates the relationship between social an physical functioning and distress in cancer survivors. British Journal of Health Psychology, 12, 363-381.

Jones, M. L. (2007). Hofstede - Culturally Questionable? Faculty of Commerce-Papers. Oxford Business \& Economics Conference (24-26 June, 2007). Oxford, UK [21.1.2012]: http://ro.uow.edu.au/comparers/370.

Kirmayer, L. J., \& Young, A. (1998) Culture and somatization: clinical, epidemiological and ethnographic perspectives. Psychosomatic Medicine, 60, 420-430.

Kirmayer, L. J., Dao, T., \& Smith, A. (1998). Somatization and psychologization: Understanding cultural idioms of distress. In: S. Okpaku (ed.), Clinical
Methods in Transcultural Psychiatry (pp. 233-265). WA: American Psychiatric Press.

Kononovas, K., \& Dallas, T. (2009). A cross-cultural comparison of perceived stress and self-efficacy across Japanese, U.S. and Lithuanian students. Psichologija, 39, 59-70.

Křivohlavý, J. (2001). Psychologie zdraví [Psychology of Health]. Praha: Portál.

Lehman, D. R., Chiu, C. Y., \& Schaller, M. (2004). Psychology and culture. Annual Review of Psychology, 55, 689-714.

Lewin, M. (2006). Cognitive Behavioral Therapy. In: Y. Jackson (ed.), Encyclopedia of Multicultural Psychology (pp. 104-106). Thousand Oaks, CA: SAGE.

Lynn, R., \& Martin, T. (1995). National differences for thirty-seven nations in extraversion, neuroticism, psychoticism and economic, demographic and other correlates. Personality and Individual Differences, 19, 403-406.

Markova, M., Moodie, E., Fait, R. M., Drozda-Senkowska, E., Plichtova, J., Eros, F., Gervais, M. C., Hoffmannova, J., \& Millerova, O. (1998). Social representations of the individual: A post communist perspective. European Journal of Social Psychology, 28, 797-829.

Markus, H. R., \& Kitayama, S. (2004). Models of agency: Sociocultural diversity in the construction of action. In: V. Murphy-Berman, \& J. Berman (eds.), Cross-cultural differences in perspectives on self (pp. 1-57). Lincoln: University of Nebraska Press.

Mathews, I. G. (2005). Self Efficacy: A Review. ABAC Journal, 25, 1-4.

Matsumoto, D. (1991). Cultural influences on facial expressions of emotion. Southern Communication Journal, 56, 128-137.

Matsumoto, D. (2001). The Handbook of culture and psychology. New York: Oxford University Press.

Matsumoto, D., \& Fletcher, D. (1996). Cultural influences on disease. Journal of Gender, Culture, and Health, 1, 71-82.

Matsumoto, D., \& Juang, L. (2007). Culture and Psychology ( $4^{\text {th }}$ ed.). Belmont, CA: Wadsworth.

McEvoy, P. M., \& Mahoney, A. E. (2012). To be sure, to be sure: Intolerance of uncertainty mediates symptoms of various anxiety disorders and depression. Behavior Therapy, 43, 533-545.

Mesquita, B., \& Markus, H. R. (2003). Culture and Emotion: Models of Agency as Sources of Cultural Variation in Emotion. In: A. Manstead, N. Frijda, \& A. Fischer (eds.), Feelings and Emotions (pp. 341358). NY: Cambridge University Press.

Miodek, A., Szemraj, P. Kocur, J., \& Ryś, A. (2007). Masked depression - history and present days. Polski Merkuriusz Lekarski, 23, 78-80.

Mirowsky, J., \& Ross, C. E. (2002). Measurement for a human science. Journal of Health and Social Behavior, 43, 152-170.
Controlling distress: a cultural view 
Mishel, M. (1990). Reconceptualization of Uncertainty in Illness Theory. Journal of Nursing Scholarship, 22, 256-261.

Mullins, L., Cote, M., Fuemmeler, B., Jean, V., Beath,W., \& Paul, R. (2001). Illness intrusiveness, uncertainty and distress in individuals with multiplex sclerosis. Rehabilitation Psychology, 46, 139-153.

Oettingen, G. (1995). Cross-cultural perspectives on self-efficacy. In: A. Bandura (ed.), Self-Efficacy in changing societies (pp. 149-176). Cambridge: Cambridge University Press.

Oyserman, D., \& Lee, S. S. (2008). Priming "culture": Culture as situated cognition. In: S. Kitayama, \& D. Cohen (eds.), Handbook of Cultural Psychology (pp. 102-142). NY: Guilford Press.

Rathod, S., \& Kingdon, D. (2009). Cognitive behaviour therapy across cultures. Psychiatry, 8, 370-371.

Ridner, S. (2004). Psychological distress: Concept analysis. Journal of Advanced Nursing, 45, 536-545.

Sawang, S., Oei, T., \& Goh, Y. (2006). Are Country and Culture Values Interchangeable? A case Example Using Occupational Stress and Coping. International Journal of Cross Cultural Management, 6, 205-219.

Scholz, U., Dona, B. G., Sud, S., \& Schwarzer, R. (2002). Is general self-efficacy a universal construct? Psychometric findings from 25 countries. European Journal of Psychological Assessment, 18, 242-251.

Schwartz, S. H. (1994). Beyond individualism and collectivism: New cultural dimensions of values. In: U. Kim, H. C. Triandis, C. Kagitcibasi, S. C. Choi, G. Yoon (eds.), Individualism and collectivism: Theory, method, and applications (pp. 85-122). Newbury, CA: SAGE.

Seeley, K. L. (2000). Cultural psychotherapy. Working with culture in the clinical encounter. Northvale, $\mathrm{NJ}$ : Jason Aronson.

Sharma, P. (2010). Measuring personal cultural orientations: scale development and validation. Journal of the Academy of Marketing Science, 38, 787-806.

Schaubroeck, J., Lam, S. S. K., \& Xie, J. L. (2000). Collective efficacy versus self-efficacy in coping responses to stressors and control: A cross-cultural study. Journal of Applied Psychology, 85, 512-525.

Shulruf, B., Hattie, J., \& Dixon, R. (2011). Intertwinement of individualist and collectivist attributes and response sets. Journal of Social, Evolutionary, and Cultural Psychology, 5, 51-65.

Staudinger, V. M., Baltes, P. B., \& Fleeson, W. (1999). Predictors of subjective physical health and global well-being: similarities and differences between the United States and Germany. Journal of Personality and Social Psychology, 76, 305-319.

Stewart, A., Ware, J., Sherbourne, C., \& Wells, K. (1992). Psychological Distress/Well-Being and Cognitive Functioning Measures. In: A. Stewart, \& J. Ware (eds.), Measuring Functioning and
Well-Being (pp. 102-142). Durham: Duke University Press.

Sue, D. W., \& Sue, D. (2003). Counseling the culturally different: Theory and practice ( $4^{\text {th }}$ ed.). New York: John Wiley.

Svoboda, M. (1999). Psychologická diagnostika dospělých [Psychological Diagnostics of Adults]. Praha: Portál.

Thompson, S. C. (1981). Will it hurt if I can control it? A complex answer to a simple question. Psychological Bulletin, 90, 89-101.

Triandis, H. C. (1995). Individualism and collectivism. Boulder, CO: Westview Press.

Varnum, M. E. W. (2008). Rapid adaptation to social change in Central Europe: changes in locus of control, attribution, subjective well-being, self-direction, and trust. Sociológia, 40, 215-235.

Wallston, K. A. (2004). Control and Health. In: N. Anderson (ed.), Encyclopedia of Health \& Behavior I (pp. 217-220). Thousand Oaks, CA: SAGE.

Wallston, K. A., Wallston, B. S., Smith, S., \& Dobbins, C. (1987). Perceived control and health. Current Psychological Research and Reviews, 6, 5-25.

Weisz, J. R., Rothbaum, F. M., \& Blackburn, T. C. (1984). Standing out and standing in: The psychology of control in America and Japan. American Psychologist, 39, 955-969.

Yamaguchi, S. (2001). Culture and control orientation. In: D. Matsumoto (ed.), The Handbook of culture and psychology (pp. 223-243). New York: Oxford University Press.

Yook, K., Kim, K. H., Suh, S. Y., \& Lee, K. S. (2010). Intolerance of uncertainty, worry, and rumination in major depressive disorder and generalized anxiety disorder. Journal of Anxiety Disorders, 24, 623-628. 